\title{
O USO DE PARÓDIAS NO ENSINO DE BIOLOGIA: RELATO DE EXPERIÊNCIA
}

\author{
Beatriz dos Santos Paixão \\ Mestrado Profissional em Ensino de Biologia pela Universidade Federal de \\ Juiz de Fora (UFJF), MG, Brasil \\ biaspaixao@gmail.com \\ Carlos Alberto Mourão Júnior \\ Pós-Doutorado em Estatística no Instituto de Matemática Pura e Aplicada (IMPA), RJ, Brasil \\ Professor Associado da Universidade Federal de Juiz de Fora (UFJF), MG, Brasil \\ camouraojr@gmail.com \\ Rodrigo Hohl \\ Pós-doutorado em Ciência do Esporte pela Universidade Estadual de \\ Campinas (UNICAMP), SP, Brasil \\ Pós-doutorado fellow pelo Sports Science Institute of South Africa (SSISA), \\ Cape Town, África do Sul \\ Pós-doutorado em Psicologia pela Universidade Federal de Juiz de Fora (UFJF), MG, Brasil \\ Professor adjunto do Departamento de Fisiologia do Instituto de \\ Ciências Biológicas da (UFJF), MG, Brasil \\ hohlrodrigo@gmail.com
}

\section{RESUMO}

O aprendizado de tópicos em biologia requer o entendimento de nomenclatura específica e não coloquial. As paródias podem aproximar a semântica cultural do aluno aos termos próprios da biologia, promovendo a aprendizagem significativa. $O$ uso de paródias foi analisado durante dois anos (2017-2019) em turmas de ensino fundamental e médio de cinco escolas públicas. Concluímos que a paródia é um instrumento didático de rememoração dos significados e da nomenclatura própria da biologia. É uma metodologia de baixo custo que trabalha de forma criativa conceitos não coloquiais e os significados associados. Entretanto, a paródia em si não gera motivação intrínseca sendo fundamental a exposição incisiva do professor trazendo segurança para o aluno e credibilidade à proposta didática.

Palavras-chave: Paródias. Relato de experiência. Aprendizagem significativa. Inovação pedagógica.

\section{THE USE OF PARODIES IN BIOLOGICAL EDUCATION: EXPERIENCE REPORT}

\begin{abstract}
Learning topics in biology requires understanding of specific and non-colloquial nomenclature. Parodies can bring the student's cultural semantics closer to biology's own terms, promoting meaningful learning. The use of parodies was analyzed for two years (2017-2019) in elementary and high school classes of five public schools. We conclude that
\end{abstract}


parody is a didactic instrument of recollection of meanings and specific nomenclature of biology. It is a low-cost methodology that creatively works non-colloquial concepts and its associated meanings. However, the parody itself does not generate intrinsic motivation. It is necessary the incisive exposure of the teacher bringing security to the student and evidencing the credibility of the didactic proposal.

Keywords: Parodies. Experience reporting. Meaningful learning. Pedagogical innovation.

Recebido: 25/12/2019. Aceito: 08/09/2020. 


\section{INTRODUÇÃO}

Talvez o maior desafio para o ensino da biologia não seja apenas explicar os fenômenos e processos biológicos. O que torna a biologia difícil para muitos alunos, tornando-os desmotivados, é a profusão de nomes (nomenclaturas) nada familiares. Os alunos se queixam, com frequência e com razão, que em biologia tudo tem um nome "diferente", que "são nomes demais para decorar".

De fato, a biologia - talvez mais do que as outras ciências naturais - apresenta um léxico à parte. Entretanto, o domínio da taxonomia e da nomenclatura correta das estruturas é condição indispensável para se atingir a meta de ensinar biologia.

Daí surge o desafio: como promover o interesse do aluno para o aprendizado da nomenclatura própria da biologia? Nesse sentido, o interesse pode ser diferenciado em interesse individual e situacional (HIDI, 2006; MENDES; BORGES, 2005). O interesse individual é um construto ligado à motivação para adquirir conhecimentos em vista de um planejamento ou propósito de longo prazo (MENDES; BORGES, 2005). O interesse situacional é dependente de condições ambientais favoráveis e é mais transitório (MENDES; BORGES, 2005). Portanto, é possível que o professor seja um agente promotor do interesse situacional dos alunos pelo objeto de estudo ao dimensionar com eficiência o meio de instrução. O resultado que se esperaria seria o engajamento produtivo como comportamento observável durante o estudo e, consequentemente, o aprendizado das habilidades e dos conceitos elementares sobre o tema.

Entendemos como aprendizagem um indivíduo captando informações do ambiente, guardando-a por algum tempo e, eventualmente, utilizando-as para orientar o seu comportamento subsequente (LENT, 2019). O conceito de aprendizagem, doravante, superpõe-se com o de memória (LENT, 2019). A relação entre aprendizagem e memória se desvenda através da abordagem cognitivista que, dentre os teóricos mais influentes encontra-se David Ausubel (1918-2008) proponente da Teoria da Aprendizagem Significativa (AUSUBEL, 1968, 2000; AUSUBEL; NOVAK; HANESIAN, 1980) e aprimorada no Brasil, já no século XXI (MOREIRA, 2011; MOREIRA; MASINI, 2011).

O núcleo duro da teoria da aprendizagem significativa diz que o principal determinante para que um aprendizado eficaz e eficiente aconteça é partir daquilo que o aluno já sabe, aquilo que lhe é familiar, porque a partir do que ele já sabe, os novos 
conhecimentos irão se ancorando e se integrando na estrutura cognitiva. AUSUBEL ([1963]) chama os conceitos que o aluno já possui de subsunçores. Entretanto, no caso da nomenclatura, talvez o aluno não tenha nenhum conceito prévio que possa servir de subsunçor. Por exemplo, a reprodução de pteridófitas, as fases da meiose, a taxonomia zoológica etc. são assuntos ensinados através de nomenclatura totalmente nova para o aluno.

Quando um novo conhecimento é completamente não-familiar, um organizador expositivo pode ser usado para promover subsunçores. A principal função de um organizador expositivo seria a de servir de ponte entre o que o aprendiz já sabe e o que precisa saber para que possa aprender significativamente o novo conhecimento (AUSUBEL, 1968, 2000). Assim, na impossibilidade de acionarmos um conceito prévio como subsunçor, podemos lançar mão de um contexto amigável que o aluno já conheça e utilizá-lo como um organizado prévio.

Um contexto amigável e familiar para o aluno pode ser promovido através da música. Por meio de músicas conhecidas e que os alunos gostem, é possível criar um solo motivador para que o aluno aprenda conteúdos menos familiares e abstratos associando-os com melodias populares. Isso é possível criando ou utilizando paródias. As paródias são releituras de composições literárias e seu uso foi reportado no ensino da biologia por outros autores (ALMEIDA; OLIVEIRA; AQUINO, 2017; BARROS; ZANELLA; ARAÚJO-JORGE, 2013; CATÃO, 2010; FERREIRA; LIMA; JESUS, 2013).

Como exposto, para justificar a aplicação das paródias usamos como referencial teórico a teoria da aprendizagem significativa. Já para descrever o relato de experiência, nosso referencial teórico é a fenomenologia de Edmund Husserl (HUSSERL, 2012). Segundo a fenomenologia, sujeito e objeto são inseparáveis no processo do conhecimento, porquanto, a consciência do sujeito que observa é sempre consciência de alguma coisa (intencionalidade da consciência) e, paralelamente, o objeto só tem sentido quando significado pela consciência que o percebe. Assim, para a fenomenologia o que importa é como o sujeito experiência as suas vivências. Não faz sentido, no método fenomenológico, interpretar, emitir juízos, ou produzir ilações sobre o fenômeno observado.

No paradigma da fenomenologia cabe realizar as duas modalidades de redução que compõem o chamado método fenomenológico. A primeira é a redução fenomenológica, que diz que o examinador deve suspender seu juízo e observar os fenômenos sem o véu cultural. 
A segunda é redução eidética, que busca encontrar a essência daquilo que é experienciado pelo observador, ou seja, o observador deve tanto relatar aquilo que ele percebeu de comum nas experiências que ele presenciou (CERBONE, 2012; SOKOLOWSKI, 2004) quanto as situações infrequentes que sejam incidentes cruciais para o entendimento da experiência relatada (COHEN; MANION; MORRISON, 2017).

Neste trabalho, pretendemos relatar as experiências sobre o uso de paródias para o ensino de biologia em três contextos didáticos: uso de paródias prontas, produção e apresentação de paródias originais e produção e apresentação das paródias originais em evento tipo concurso/festival.

\section{DESCRIÇÃO DO CENÁRIO DE PRÁTICA}

As paródias foram utilizadas em diversas turmas do ensino médio e do ensino fundamental. A análise em sala de aula foi realizada durante um período de dois anos, do segundo semestre de 2017 a março de 2019, em cinco escolas, sendo elas: E.E. São Sebastião, localizada no Povoado de São Sebastião da Barra e E.E. Altivo Leopoldino de Souza, ambas localizadas no município de Espera Feliz-MG; E.E. Prefeito Jayme Toledo, situada no município de Caiana-MG; E.E. de ensino fundamental e médio, localizada em um vilarejo da cidade de Fervedouro-MG; E.E.E.F.M. Oscar de Almeida Gama em Araraí, pertencente ao distrito de Alegre-ES.

As escolas E.E. São Sebastião, E.E. de ensino fundamental e médio e E.E.E.F.M. Oscar de Almeida Gama possuem a maioria alunos provenientes da zona rural, pois se localizam em distritos ou vilarejos. Também contam com um número menor de alunos se comparadas às demais. As escolas E.E. Prefeito Jayme Toledo e E.E. Altivo Leopoldino de Souza, por sua vez, contam com uma média de $40 \%$ do alunado proveniente da zona rural, o restante pertence à zona urbana, uma vez que tais escolas estão localizadas dentro da cidade.

Na escola E.E. São Sebastião, no ano de 2017, a metodologia foi aplicada nas turmas do primeiro ano do ensino médio, compostas de 12 alunos, segundo ano do ensino médio, 17 alunos e no sétimo ano do ensino fundamental, 22 alunos. No ano de 2018, foi aplicada a mesma metodologia de trabalho nas turmas do primeiro ano do ensino médio, 16 alunos, 
segundo ano do ensino médio, 10 alunos, sétimo ano do ensino fundamental, 20 alunos e oitavo ano do ensino fundamental, 23 alunos.

Na E.E. Prefeito Jayme Toledo, município de Caiana-MG, as paródias foram aplicadas no ano de 2017, na turma do segundo ano do ensino médio, 23 alunos e no terceiro ano do ensino médio, 22 alunos. Na E.E. de ensino fundamental e médio, por sua vez, o trabalho ocorreu no ano de 2018, tendo como objeto de estudo a aplicação da metodologia na turma de sexto ano do ensino fundamental, 33 alunos.

Na E.E.E.F.M. Oscar de Almeida Gama a intervenção foi realizada em 2019 com as turmas do sexto ano do ensino fundamental, 12 alunos e do oitavo ano do ensino fundamental, 11 alunos. Por fim, na E.E. Altivo Leopoldino de Souza o trabalho ocorreu no ano de 2019 com o primeiro ano do ensino médio, 29 alunos. O relato inclui 13 turmas, sendo 7 turmas de ensino médio e 6 turmas de ensino fundamental totalizando 250 alunos, sendo 129 alunos do ensino médio e 121 alunos do ensino fundamental.

No ensino médio de todas as escolas trabalhadas foram ministradas duas aulas semanais de Biologia. Já no ensino fundamental, foram ministradas duas aulas semanais no sétimo ano da E. E. São Sebastião, três aulas semanais na turma de sexto ano das escolas de ensino fundamental e médio, quatro aulas semanais nas turmas sexto ano da E.E.E.F.M. Oscar de Almeida Gama e cinco aulas semanais na turma do oitavo ano da E.E.E.F.M. Oscar de Almeida Gama.

\section{REGISTRO DAS INFORMAÇÕES QUALITATIVAS E COMPOSIÇÃO DO RELATO}

A primeira autora deste trabalho (BSP) elaborou as intervenções didáticas sendo a professora responsável por todas as turmas de alunos que compõem o relato. A professora registrou os fenômenos ocorridos na sala de aula em diário de campo imediatamente após as aulas ou ao final do expediente de trabalho nas escolas. Trata-se, portanto, de um relato a partir de uma observadora participante. O registro no diário de campo teve como enfoque os comportamentos que denotassem engajamento ou desengajamento no cântico, elaboração e/ou apresentação das paródias. O relato de experiência redigido pela observadora foi analisado pelos demais autores deste trabalho (CAMJ e RH) que fizeram questionamentos com ênfase no engajamento/desengajamento dos alunos e no comportamento da professora em vista de promover o interesse situacional e superar a 
tendência ao desengajamento. A triangulação entre os autores teve como objetivo estimular a rememoração dos eventos ocorridos e verificar se informações relevantes poderiam estar ausentes no relato. Após as indagações, a professora/observadora adequou o relato inicialmente apresentado até sua formatação final sintetizada neste presente trabalho.

\title{
4 APLICAÇÃO DAS PARÓDIAS
}

\subsection{Paródias prontas}

Embora todos os autores desse trabalho tenham participado da atividade, a intervenção mais direta foi da primeira autora (professora BSP). Para o uso de paródias prontas fizemos uma introdução do tema a ser trabalhado. Iniciamos o processo com uma aula expositiva, nela buscamos apresentar o assunto e resgatar os subsunçores dos alunos referentes ao conteúdo a ser tratado. Após a introdução, distribuímos uma cópia da paródia retirada da internet para cada aluno, para que ela fosse colada no caderno. A professora (BSP) cantou uma vez a paródia e depois cantou com os alunos várias vezes até que eles se acostumassem com a letra e a melodia. Fizemos uma análise e discussão da letra da música com os alunos. A professora procurou sanar as dúvidas relacionadas aos conteúdos trabalhados presentes na música.

A paródia da música "Bang", da cantora pop Anitta, foi trabalhada nas turmas de primeiro ano do ensino médio e sétimo ano do ensino fundamental. O conteúdo versava sobre a teoria da abiogênese e biogênese. Nele constam os experimentos de Redi e Pasteur e identificação das diferenças entre as ideias de cada um.

Paródia 1 - Teoria da Abiogênese X Biogênese (Bang, Anitta).

\author{
Não deu pra provar \\ Só por Redi que ela surge assim \\ Foi preciso de Pasteur testar e garantir \\ Uh, uh, uh, uh, uh $(3 x)$ \\ Vem, deixa eu te explica o que vai ser \\ Como a vida fez pra acontecer \\ Tem que se ligar \\ No que eu passar e estudar \\ Então vem, vem \\ Quando a roupa suja pelo chão
}


Ou uma carne em putrefação

Pode ter certeza, vida nascerá! Bem de lá

Ihhh! Redi duvida, testa e justifica

Dizendo que a mosca vem voando Ihhh! Pra contrariar, Need ferveu uma água

E viu bichinhos se multiplicando Não deu pra provar

Só por Redi que ela surge assim

Foi preciso de Pasteur testar e garantir Uh, uh, uh, uh, uh (3x)

Vem, Pasteur da França pra dizer

"Não é força vital que faz viver",

Tem microorganismos soltos pelo ar Vai contaminar

Só depois de muita discussão

É que chegaram a uma conclusão

A biogênese resolveram aceitar Sem blá, blá, blá.

Ihhh! Redi duvida, testa e justifica

Dizendo que a mosca vem voando

Ihhh! Pra contrariar, Need ferveu uma água

E viu bichinhos se multiplicando

Não deu pra provar

Só por Redi que ela surge assim

Foi preciso de Pasteur testar e garantir Uh, uh, uh, uh, uh (3x)

Fonte: Bio Os Feras (2019).

A paródia "Ciranda das Organelas" foi utilizada nas turmas de primeiro ano do ensino médio e oitavo ano do ensino fundamental. Essa paródia tinha por objetivo uma compreensão melhor sobre o conteúdo "Células", especificamente no que diz respeito a algumas organelas citoplasmáticas. Nesse caso, fora realizada uma aula expositiva, após a exibição de um vídeo sobre as organelas e, por fim, a aplicação da paródia.

Paródia 2 - Ciranda das Organelas (Ciranda, Cirandinha, Cantiga Popular).

\footnotetext{
Mitocôndria, mitocôndria é quem faz respiração Ribossomo sintetiza proteínas de montão O Complexo de Golgi armazena secreção Lisossomo tem enzimas "prá" fazer a digestão O retículo apresenta a função de transportar O centríolo participa da divisão celular
}

Fonte: Ciranda das Organelas (2012). 
Nas turmas do segundo ano do Ensino médio foram trabalhadas outras duas paródias prontas, retiradas da internet, que abordavam os conteúdos sobre o Reino Plantae, Briófitas e Pteridófitas. Para a abordagem do tema, os estudantes participaram de uma aula expositiva para logo após conhecerem a paródia e discutirem sua letra/conteúdo.

Paródia 3 - A Briófita (Banho de Lua, Celly Campelo).

\author{
A briófita é pequena \\ Sem sistema vascular \\ Anterozoide, oosfera \\ Tão querendo fecundar \\ Isso é uma desvantagem \\ Pois, dependem d'água \\ Plim, plim, plim \\ Caem os esporos \\ Plim, plim, plim \\ Vão germinar \\ Uma nova planta \\ Eles irão formar \\ Fonte: A Briófita (2010).
}

Paródia 4 - Pteridófitas (Lepo Lepo, Psirico).

\author{
Ah, sei muito bem o que fazer \\ O reino vegetal agora vamos estudar \\ Ah, Pteridófita vai ser \\ Tem vasos condutores e são hermafroditas \\ Não tem sementes, flores nem frutos \\ A água ajuda a reprodução \\ Os soros são pontinhos escuros \\ Que liberam os esporos e estes caem no chão \\ É a cavalinha, é a avenca \\ E tem a minha samambaia também \\ Pteridó dó dó dó dó dó dó \\ Pteridófitas \\ Fonte: Souza (2015).
}

\title{
4.2 Produção e apresentação de paródias originais
}

Para a produção de paródias, foram utilizadas duas etapas de apresentação. A primeira consistiu em produzir a paródia e somente apresentar em caráter informal, a segunda, além de produzi-la, apresentá-la em um concurso. 
A produção de paródias em forma de apresentação se direcionou às turmas de primeiro ano do ensino fundamental a partir do tema de organelas citoplasmáticas. Foram observadas dez etapas sequenciais para a produção das paródias.

Na primeira etapa deu-se a introdução da proposta. Nesse ínterim, o tema sobre organelas citoplasmáticas foi discutido em aula expositiva e, logo após, explicou-se aos alunos o que viria a ser uma paródia. Dessa forma, com o fito de dinamizar a aula, aplicou-se a paródia Ciranda das organelas, descrita anteriormente. Também fez parte da atividade a discussão entre professores e alunos sobre a letra da paródia, cabendo ao profissional da educação mostrar os caminhos que levaram tal paródia a ser produzida. Oportunizou-se, assim, aos alunos a troca de opiniões e a apresentação de dúvidas sobre o assunto.

A segunda etapa contou com a divisão da turma em grupos de no máximo cinco integrantes. Na divisão, preocupou-se em misturar os alunos que não gostavam de paródias com os aqueles que gostavam. O próximo passo foi a escolha do tema. Ficou decido o conteúdo sobre organelas citoplasmáticas, explicado pelo professor. A quarta etapa consiste na orientação dos alunos. O professor exerce aqui o papel de dirigente, dando algumas dicas sobre possíveis músicas, explicando a importância da escolha de músicas que sejam conhecidas pela maioria das pessoas, tais como: músicas de cantiga de rodas, músicas da atualidade que fixam na cabeça, enfim, alguma música em que esteja na "cabeça do povo", valorizando também o gosto musical de cada um.

Após a escolha da música, foi pedido aos alunos que eles escrevessem a letra original para só então começar a produzir a paródia. Uma semana era o prazo de entrega do material final. Assim que entregaram a letra, a professora realizou a leitura e conferiu se os conceitos da matéria foram aplicados corretamente.

As paródias foram digitadas e distribuídas em cópias para todos os alunos daquela sala. Dessa forma, todos tiveram em mãos tanto as suas paródias quanto as dos demais grupos. A etapa de apresentação foi motivada pela professora, respeitando a individualidade de cada um e não obrigando ninguém a cantar. A ordem da apresentação aconteceu em forma de sorteio, oportunizando uma apresentação aleatória/neutra, sem interferência da professora na escolha dessa ordem. Os alunos, por seu turno, foram orientados a ficar em silêncio durante as apresentações, não podendo discutir nada entre o seu grupo. Assim, participaram da aula levando em consideração as regras sobre fazer silêncio e escutar com respeito a apresentação dos colegas, não sendo permitidos abusos ou deboches. 
Aos alunos permitiu-se o uso de fundo musical em forma de karaokê, instrumentos musicais, ou apenas as suas vozes cantadas. Dessa forma, a apresentação dos grupos ocorreu de acordo com a vontade de cada equipe. Dois grupos utilizaram o fundo musical e os demais apenas cantaram a paródia.

O trabalho foi avaliado de forma contínua durante todo o processo de elaboração e apresentação das paródias. A nota final do trabalho ficou dividida em duas partes: metade considerando a produção das paródias e metade sua apresentação.

Um grupo de alunos, por exemplo, produziu uma paródia a partir da música "Se essa rua fosse minha", com o tema Organelas celulares.

Paródia 5 - Célula Animal (Se Essa Rua Fosse Minha, Cantiga Popular).

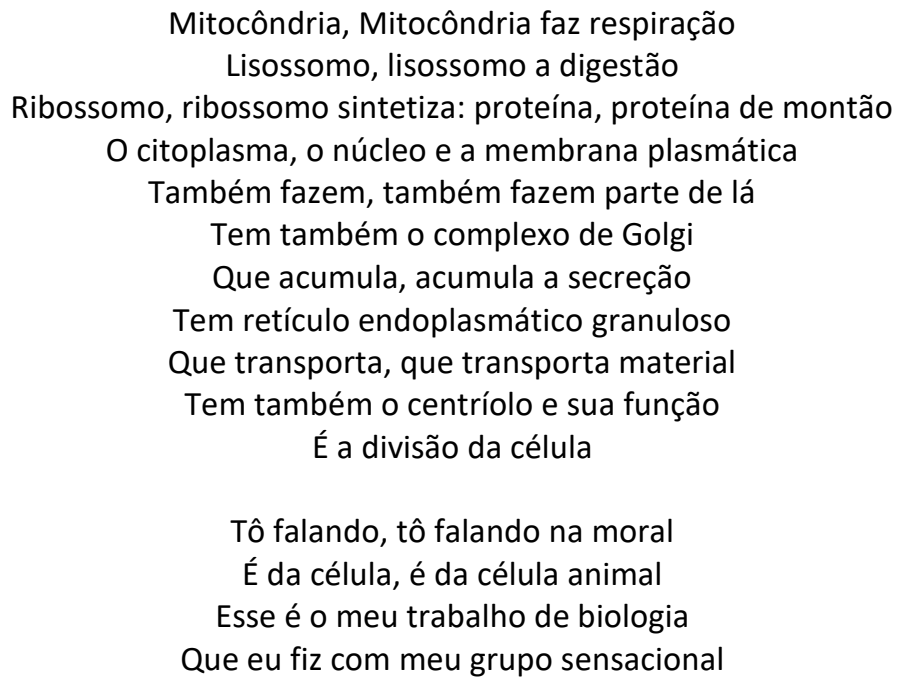

Fonte: Autor (2020) adaptado do grupo de alunos Roberta, Ângelo, Tiago, Vinícius e Matheus.

Em uma turma do terceiro ano do ensino médio solicitou-se a produção de paródias sobre o tema das leis de Mendel. Como forma de teste não foram seguidas as etapas acima, portanto, não houve orientação aos alunos no processo de produção das paródias. Apenas dois grupos apresentaram, não havendo motivação por parte dos alunos para a realização da atividade proposta.

O mesmo método foi aplicado em uma turma do primeiro ano do ensino médio. Pediu-se a criação de paródias considerando o tema "nutrientes". Sem acompanhamento e motivação da professora, os alunos teriam que fazer as suas próprias paródias. Alguns alunos iniciaram os trabalhos, porém não concluíram. Nenhum grupo apresentou. 


\subsection{Apresentação das paródias em concurso}

Ocorreu a produção de paródias e apresentação em forma de concurso nas turmas de ensino fundamental. Diversos temas foram abordados, tais como fungos, preservação da água, os estados físicos da água e organelas citoplasmáticas.

Nessas turmas, foram aplicadas as mesmas dez etapas trabalhadas no método de apresentação de paródias já descritos, isto é, com acompanhamento e motivação da professora. Também se mostrou necessário o acréscimo de mais algumas etapas. A primeira delas contemplava a motivação do espírito participativo e não competidor, criando neles o desejo de participar do concurso.

Foi escolhida uma banca julgadora composta de três pessoas que não pertenciam àquela sala, geralmente funcionários da escola. Os alunos foram pontuados entre 05 a 10 pontos por cada membro da banca julgadora a partir dos seguintes critérios:

1 - Coerência com o tema proposto;

2 - Originalidade e criatividade;

3 - Apresentação geral (desenvoltura, animação, harmonia e empolgação do grupo).

A nota final foi a média aritmética simples das notas dada pelos jurados. A paródia que alcançou a maior nota ganhou. Em caso empate, o critério de desempate seria a maior nota computada no critério 1,2 e 3, respectivamente, enquanto perdurasse o empate. Se ainda houvesse nota igual entre os grupos, uma votação da turma resolveria a questão.

A apresentação do concurso, feita pela professora, ocorreu simulando um concurso de televisão, visando sempre à descontração e à dinâmica do momento. Os grupos se apresentaram na ordem do sorteio. No final, a professora ajudou a contabilizar a votação, informou o resultado final, presenteando cada integrante da equipe vencedora com uma caixa de chocolate.

Todos os participantes receberam agradecimentos, de maneira a valorizar o trabalho desenvolvido por todas as equipes. Nessa fala, destacou-se a importância maior da atividade que é o aprendizado, a participação e o envolvimento da turma na metodologia proposta.

Para exemplificar, uma paródia criada para o concurso teve como autores estudantes do sexto ano do ensino fundamental, os quais abordaram em sua produção "Os 
estados físicos da água". A música escolhida por eles foi "Aí já era", da dupla sertaneja Jorge e Mateus.

Paródia 6 - Estados Físicos da Água (Aí Já Era, Jorge e Mateus).

$$
\begin{gathered}
\text { Para pra pensar } \\
\text { Porque eu já estudei } \\
\text { O gelo é sólido } \\
\text { Esse estado eu já sei } \\
\text { De repente } \\
\text { Ocorre uma tal de fusão } \\
\text { E o gelo vira água outra vez } \\
\text { E quando o líquido evapora } \\
\text { Por causa natural. } \\
\text { Quando o liquido ferve } \\
\text { Por alta pressão } \\
\text { Quando o liquido some } \\
\text { Por calefação } \\
\text { Torna-se gasoso } \\
\text { Torna-se gasoso } \\
\text { E aí já era } \\
\text { É hora de retornar } \\
\text { Do gás para o sólido } \\
\text { Sublimação vamos lá } \\
\text { Do gás para o líquido } \\
\text { Ocorre a liquefação } \\
\text { Do líquido para o sólido } \\
\text { É a solidificação(BIS) }
\end{gathered}
$$

Fonte: Autor (2020) adaptado do grupo de alunos Vanessa, Fernanda e Dhionatan.

Em outro exemplo, um grupo de alunos do sétimo ano do ensino fundamental trabalhou o conteúdo "fungos" com a música "Olha a Explosão" do MC Kevinho.

Paródia 7 - Os Fungos (Olha a Explosão, Mc Kevinho).

Alguns fungos são terroristas

São especialistas

Causam mal para as pessoas e também dor de barriga

Alguns fungos são terroristas

São especialistas

Causam mal para as pessoas e também dor de barriga

Causam mal para as pessoas e também dor de barriga

Outros que na comida o gosto é muito bom

Outros que na comida o gosto é muito bom 


\author{
Olha a explosão \\ Tipo uma comida que tem o fungo que é o pão \\ O pão com salame que é muito bom \\ Muito bom também é o champignon \\ tu bota na carne e fica muito bom, bom, bom, bom, bom. \\ Mas se você não souber qual você tá comendo \\ Tu fica muito malzão \\ Tu pode morrer se não prestar atenção,ção, ção, ção, ção
}

Fonte: Autor (2020) adaptado do grupo de alunos Pedro, Marcelo, Caique, José Armando e Tassiele.

\title{
5 DISCUSSÃO
}

Passaremos agora a apresentar e discutir o comportamento dos alunos que foram observados em todas as turmas que integram este relato. Nossa intenção é relatar a experiência tendo como referências as ações e falas dos alunos que denotem engajamento ou desengajamento à proposta de tarefa de aprendizagem (i.e. canto e elaboração de paródias). Ademais, a professora/observadora participante, relatou as suas próprias atitudes em vista de motivar o interesse dos alunos pela proposta didática.

O primeiro destaque foi a necessidade de motivação. Poucos alunos se propõem a cantar ou criar uma paródia se não forem motivados para tal atividade. Dessa forma, indicamos que o professor precisa ser criativo na apresentação das paródias e na introdução do tema a ser trabalhado. Isso não significa se expor de forma mirabolante ou fazer coisas extraordinárias, é saber usar uma frase bem entonada, proporcionar uma introdução ao tema que inspire emoção, afinal, aprendemos com aquilo que nos motiva, que nos emociona (HASCHER, 2010). Essa primeira parte é de extrema importância, pois introduzirá o tema aos alunos cativando neles o anseio de participar.

Quando a professora apenas anunciou que a atividade seria a confecção de uma paródia, como se fosse uma atividade como outras já vivenciadas, não provocou nos alunos o interesse situacional. Esse fato foi observado em uma turma do terceiro ano do ensino médio e em outra do primeiro ano do ensino médio. Em ambas houve a tão somente solicitação da produção de paródias, mas sem o incentivo insistente e criativo da professora os alunos não apresentaram as paródias. Cabe ressaltar que a apresentação das paródias contabilizava nota para aprovação na disciplina, mesmo assim, os alunos optaram por não apresentarem a tarefa. Nestes dois casos, a professora reformulou a didática, o momento e 
a forma de avaliação para atingir o objetivo de aprendizagem sem prejudicar o andamento da disciplina.

Trabalhar com paródias não demanda a necessidade de sempre criar um material novo. Nada impede que o professor trabalhe com uma paródia pronta, seja retirada do livro, revista ou da internet. Ela funciona como um organizador expositivo que tem a intenção de trabalhar determinados conteúdos de forma lúdica e significativa. Portanto, a paródia pode ser aquela que foi criada ou aquela já existente. Independentemente da forma que será escolhida pelo profissional, deverá ser usada em momentos certos e de forma que inspire o aluno a estudar o conteúdo. Nesse sentido, fizemos a opção de apresentar as paródias sempre após a introdução dos conceitos e proposições a serem trabalhados nas mesmas.

Percebemos também que planejar o uso de paródias é crucial. Não pode ser feito subitamente, ou aplicado de qualquer forma, no improviso. Isso desmotiva o aluno porque ele percebe quando aula é previamente planejada, quando o conteúdo foi pensado, quando o professor empregou tempo na atividade. A paródia precisa ser contextualizada num planejamento didático mais amplo que dê embasamento para que ela seja aplicada. Não importa aqui se são paródias prontas ou criadas, é necessária uma organização, uma sequência a seguir, do contrário o aluno percebe aquela atividade como algo banal. Se o ambiente não for previamente preparado, algo que poderia ser usado para ajudar no processo de aquisição de conhecimento vira pretexto para bagunça e brincadeira.

Em qualquer um dos métodos propostos (criação ou utilização de material já existente), é interessante trabalhar previamente o assunto a ser estudado, seja valendo-se de aula expositiva, slides, livro, quadro, vídeo ou aulas práticas. O aluno precisa associar os novos conhecimentos com a possibilidade de organizá-los em formato de paródia. Dessa forma, a paródia funcionará como suporte, onde o professor poderá retornar a ela quando achar necessário durante as aulas. Todavia, o professor não poderá substituir a explicação do conteúdo pela paródia, pois ela visa a aprendizagem significativa da nomenclatura. Portanto, os conceitos e significados relacionados com a nomenclatura precisam ser abordados com meios didáticos complementares. Quanto ao educando, ele poderá posteriormente lembrar do conteúdo, seja para avaliações, rodas de debates ou outros momentos associando as nomenclaturas presentes na paródia com os conceitos e significados que os abarcam. Após as avaliações, foi comum ouvir relatos dos alunos dizendo que as paródias foram importantes e que com elas foi possível associar os conhecimentos 
adquiridos às questões da prova, respondendo-as com mais facilidade. Uma aluna disse certa vez que cantou durante a prova e que conseguiu aprender o conteúdo.

Com relação à rememoração de conteúdo, observamos que após a aplicação da paródia "Ciranda das Organelas" os alunos cantavam, relembravam e quando iam fazer outras atividades de aprendizagem, cantavam novamente. Por serem diversas organelas e cada uma desempenhar uma função específica, sintetizar este conteúdo como paródia gerou o engajamento para a aprendizagem de um assunto abstrato e com pouca relação com o cotidiano. Ressaltamos que a "Ciranda das Organelas" foi aplicada após exibição de um filme didático como introdução do conteúdo a ser trabalhado como paródia.

Um ponto positivo que percebemos durante o cântico das paródias é que a biologia possui palavras de difícil pronúncia e, quando a pessoa não está habituada a essas palavras, a paródia ajuda a torná-las mais familiares e os alunos conseguem desenvolver melhor a pronúncia. Por exemplo, o reino vegetal foi trabalhado no segundo ano do ensino médio. Introduzir esse reino é desafiador, pois os alunos acham os nomes das principais divisões desse reino (briófitas, pteridófitas, gimnospermas e angiospermas) complexos, difíceis de pronunciar. Então, trabalhamos a paródia pronta logo após a aula expositiva no início do conteúdo, tornando as palavras mais familiares para eles. Nesse caso, trabalhamos as paródias prontas: "Briófitas", música "Tomo um banho de lua", da cantora Celly Campello, e a paródia "Pteridófitas", música "Lepo Lepo", do cantor Psirico. Para o uso das paródias prontas, as ações devem ser pautadas em músicas familiares para os alunos, mas, antes de tudo, o professor precisa se inteirar da letra, compreender o ritmo, ensaiar em casa para então poder levar à sala. Primeiramente, entrega-se a letra aos alunos ou é solicitada sua cópia do quadro. No caso, sugerimos entregar a letra para ganhar mais tempo de aula.

Trabalhamos as paródias prontas em diversos momentos, pois elas dão uma flexibilidade maior em dar continuidade na matéria. Elas podem ser encontradas, na maioria das vezes, na internet, disponibilizadas em sites, blogs, YouTube etc. É preciso somente saber filtrar a paródia a ser trabalhada. Esse filtro poderá ser pautado em diversos fatores, como por exemplo: conteúdo aplicado de forma correta, tema a ser trabalhado e se a música é conhecida.

No início, quando se apresenta uma paródia pronta, percebe-se um certo acanhamento por parte de alguns, outros já tentam cantar por conta própria, por isso é preciso cantar diversas vezes, para que quebre o gelo, supere a vergonha e os alunos se 
sintam mais soltos para cantar atingindo os mais tímidos. Pode-se incentivar uma saudável competição entre lados da turma, meninos contra meninas, enfim, inspirar neles a vontade de "soltar o gogó" e cantar. Isso é importante para ajudar a aprender a música e deixar a aula mais descontraída.

O primeiro momento de apresentação de uma paródia pronta é crítico. O professor precisa motivar a turma e não desistir nas primeiras tentativas. Em muitas turmas os alunos não cantam logo no início, o professor precisa insistir, propor que é uma metodologia que precisa do apoio e interação de todos. Muitos professores sentem dificuldades nesse ponto de aplicação, pois logo no início os alunos não se interessam totalmente. Por isso, orientamos os professores a insistirem nesse início passando credibilidade e segurança na proposta.

Incentivamos também a produção de paródias, atividade que demanda um pouco mais de tempo. Nesse caso, sugerimos que se apresente uma paródia pronta para os alunos e, após isso, motive-os a produzirem também. Não é preciso partir para uma nova criação toda as vezes, mas a produção incentiva a busca pelo conteúdo e a aprendizagem por investigação. Uma característica importante da apresentação das paródias produzidas pelos alunos é que durante as apresentações o professor poderá debater a letra com os alunos e sanar as dúvidas que forem surgindo. Para tanto, é muito importante que o professor receba as paródias antes das apresentações para estabelecer uma estratégia de intervenção durante as mesmas. Nesse sentido, a aprendizagem torna-se significativa, pois o professor irá partir do conhecimento que os alunos já sabem após o trabalho investigativo de elaboração das paródias.

Não observamos diferença em trabalhar paródias em escolas da zona rural e urbana, ambas mostraram a mesma participação e entrosamento. Em relação à quantidade de alunos em sala, em turmas menores o professor consegue dar um maior suporte durante o processo de produção de paródias, mas a aplicação dessa metodologia em turmas com elevado número de alunos também é viável, pois os alunos estarão em pequenos grupos e o professor poderá orientá-los no decorrer da atividade. 


\section{CONCLUSÃO}

Em síntese, pudemos concluir que a paródia é uma metodologia de baixo custo que auxiliou no processo de ensino/aprendizagem, pois motivou os alunos e provocou neles o interesse pelo estudo. Ademais, trabalha de forma dinâmica e criativa os conteúdos que seriam difíceis de aprender de maneira tradicional, além de auxiliar os alunos a revisarem mentalmente a matéria estudada. A partir da experiência, indicamos que o uso de paródias tem potencial para ser aplicado em qualquer turma e disciplina de ensino fundamental e médio. A paródia pronta, retirada da internet, ajuda no processo de ensino e pode ser usada com mais frequência do que a produção de paródias inéditas, pois aquela se aplica mais rapidamente e atinge bons resultados, seja na compreensão do conteúdo, revisão e motivação. Entretanto, a paródia não gera motivação intrínseca no aluno de imediato, é fundamental a exposição incisiva do professor trazendo segurança para o aluno e credibilidade à proposta didática.

\section{REFERÊNCIAS}

A BRIÓFITA é pequena. Professora Andréia Fotografia e Biologia, [S. I.], 2010. Disponível em: http://andreia-biologia.blogspot.com/2010/05/briofita-epequena.html. Acesso: 19 jan. 2019.

ALMEIDA, E. F.; OLIVEIRA, E. C.; AQUINO, S. F. Proposta para o ensino de zoologia dos vertebrados a partir de paródias. Revista de Estudos e Pesquisas sobre Ensino Tecnológico (EDUCITEC), [S. I.], v. 3, n. 6, 2017. Disponível em: https://www.sumarios.org/artigo/proposta-para-o-ensino-de-zoologia-dos-vertebradospartir-de-par\%C3\%B3dias. Acesso em: 29 jul. 2019.

AUSUBEL, D. P. Psychology of meaningful verbal learning: an introduction to school learning. New York: Grune \& Stratton, [1963].

AUSUBEL, D. P. Educational psychology: a cognitive view. New York: Holt, Rinehart and Winston, 1968.

AUSUBEL, D. P. Aquisição e retenção de conhecimentos: uma perspectiva cognitiva. Lisboa: Plátano Editora, 2000.

AUSUBEL, D. P.; NOVAK, J. D.; HANESIAN, H. Psicologia educacional. 2. ed. Rio de Janeiro: Interamericana, 1980. 
BARROS, M. D. M.; ZANELLA, P. G.; ARAÚJO-JORGE, T. C. A música pode ser uma estratégia para o ensino de Ciências Naturais? Analisando concepções de professores da educação básica. Ensaio Pesquisa em Educação em Ciências, [S. I.], v. 15, n. 1, p. 81-94, jan./abr. 2013. Disponível em: https://www.scielo.br/scielo.php?pid=S1983-

21172013000100081\&script=sci_abstract\&tlng=pt. Acesso em: 29 jul. 2019.

BIO OS FERAS. Teoria da abiogênese $\mathbf{x}$ biogênese. [S. I.], 2019. Disponível em: https://www.facebook.com/pg/BIOOSFERAS-1036053709800173/posts/. Acesso em: 19 jan. 2019.

CATÃO, V. M. C. Música e escola: um estudo sócio-histórico sobre musicalização. Revista Uniabeu, v. 3, n. 5, p. 114-127, set./dez. 2010. Disponível em:

https://revista.uniabeu.edu.br/index.php/RU/article/view/61. Acesso em: 29 jul. 2019.

CERBONE, D. R. Fenomenologia. Petrópolis: Vozes, 2012.

CIRANDA DAS ORGANELAS. [S. I.: s. $n$.], 2012. 1 vídeo (2 min). Publicado pelo canal ryuuw. Disponível em: https://www.youtube.com/watch?v=R5a_pRfnp8o. Acesso em: 19 jan. 2019.

COHEN, L.; MANION, L.; MORRISON, K. Research methods in education. 8. ed. London: Routledge, 2017.

FERREIRA, G.; LIMA, M. M. C.; JESUS, R. S. Paródias como estratégia no ensino de biologia com intermediação tecnológica. In: CONGRESSO INTERNACIONAL ABED DE EDUCAÇÃO A DISTÂNCIA, 19., 2013, Salvador. Anais [...]. Salvador: EMITEC/SEC, 2013. Disponível em: http://www.abed.org.br/congresso2013. Acesso em: 29 jul. 2019.

HASCHER, T. Learning and Emotion: perspectives for theory and research. European Educational Research Journal, [S. I.], v. 9, n. 1, p. 13-28, 2010. Disponível em: https://journals.sagepub.com/doi/abs/10.2304/eerj.2010.9.1.13. Acesso em: 29 jul. 2019.

HIDI, S. Interest: a unique motivational variable. Educational research review, [S. I.], v. 1, n. 2, p. 69-82, 2006. Disponível em: https://www.researchgate.net/publication/223832634_Interest_A_unique_motivational_va riable. Acesso em: 29 jul. 2019.

HUSSERL, E. Investigações lógicas: investigações para a fenomenologia e a teoria do conhecimento. Rio de Janeiro: Forense Universitária, 2012.

LENT, R. Cérebro aprendiz: neuroplasticidade e educação. Editora Atheneu, Rio de Janeiro, 2019.

MENDES, I.; BORGES, O. Interesse de estudantes sobre temas de Biologia. In: ENCONTRO NACIONAL DE PESQUISA EM EDUCAÇÃO EM CIÊNCIAS, 5., 2005, Bauru. Atas [...]. Bauru: Associação Brasileira de Pesquisa em Educação em Ciências, 2005. Disponível em: http://abrapecnet.org.br/atas_enpec/venpec/conteudo/artigos/1/pdf/p364.pdf. Acesso em: 29 jul. 2019. 
MOREIRA, M. A. Aprendizagem significativa: a teoria e textos complementares. São Paulo: Livraria da Física, 2011.

MOREIRA, M. A.; MASINI, E. F. S. Aprendizagem significativa: a teoria de David Ausubel. 2. ed. São Paulo: Centauro, 2011.

SOUZA, J. N. Paródia pteridófitas. [S. I.: s. n.], 2015. 1 vídeo (2 min). Publicado pelo canal \{com\}Ciência - Profa Juliana Nogueira. Disponível em:

https://www.youtube.com/watch?v=d08q5pByFGM. Acesso em: 19 jan. 2019.

SOKOLOWSKI, R. Introdução à fenomenologia. São Paulo: Edições Loyola, 2004. 